\title{
AS TECNOLOGIAS NA EDUCAÇÃO: \\ DESAFIOS E ENFRENTAMENTOS À TRADIÇÃO INSTRUMENTAL ${ }^{1}$
}

TÍTULO TECHNOLOGIES IN EDUCATION:

CHALLENGES AND CONFRONTATIONS TO THE INSTRUMENTAL TRADITION

\section{TECNOLOGÍAS EN EDUCACIÓN: DESAFÍOS Y ENFRENTAMIENTO TRADICION INSTRUMENTAL}

Adilson Cristiano Habowski ${ }^{2}$

\section{RESUMO}

O presente texto é uma resenha da dissertação de Mestrado defendida no Programa de Pós-Graduação em Educação da Universidade La Salle, de Adilson Cristiano Habowski, sob orientação da professora Dra. Elaine Conte, intitulada Teoria crítica da tecnologia e educação: desafios contemporâneos. O estudo, de abordagem hermenêutica, discute sobre os desafios das tecnologias na educação com o propósito de suspeitar da razão técnica, unidirecional, de receitas tecnocráticas oriundas de uma tradição utilitarista e programada de ensino do mundo empresarial, tendo por bases a Teoria Crítica e a Filosofia da Tecnologia. A pesquisa procura reconhecer o potencial de linguagem mobilizadora, reconstrutiva e questionadora da tecnologia na educação, que pela sua ubiquidade pode vincular desorientações, alienações e imprecisões, assim como gerar relações políticas de resistência diante das injustiças sociais.

PALAVRAS-CHAVE: Tecnologias. Educação. Desafios. Instrumentalidade técnica.

\section{ABSTRACT}

This text is a review of the Master's thesis defended in the Graduate Program in Education of La Salle University, by Adilson Cristiano Habowski, under the guidance of Professor Dra. Elaine Conte, entitled Critical theory of technology and education: contemporary challenges. The hermeneutic study discusses the challenges of technologies in education with the purpose of suspecting the technical, unidirectional reason of technocratic recipes from a utilitarian and programmed tradition of teaching the business world, based on Critical Theory and Philosophy of Technology. The research seeks to recognize the potential of mobilizing, reconstructive and questioning language of technology in education, which by its ubiquity can link disorientations, alienations and inaccuracies, as well as generate political relations of resistance in the face of social injustices.

Submetido em: 09/06/2020 - Aceito em: 24/07/2020 - Publicado em: 18/08/2020.

1 Apoio: Conselho Nacional de Desenvolvimento Científico e Tecnológico (CNPq) e Fundação de Amparo à Pesquisa do Estado do Rio Grande do Sul (FAPERGS).

2 Doutorando em Educação pela Universidade La Salle/UNILASALLE. Canoas/RS - Brasil. Membro do Núcleo de Estudos sobre Tecnologias na Educação - NETE/UNILASALLE/CNPq. E-mail: adilsonhabowski@hotmail.com 


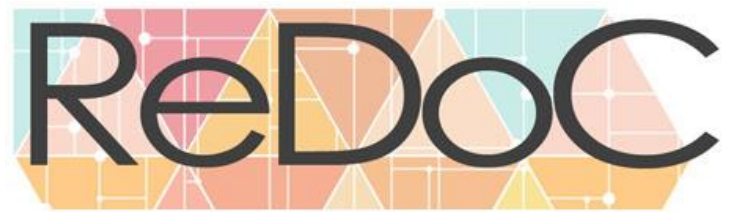

\section{Revista Docência e Cibercultura}

KEYWORDS: Technologies. Education. Challenges. Technical instrumentality.

\section{RESUMEN}

Este texto es una revisión de la disertación de maestría defendida en el Programa de Posgrado en Educación en la Universidad La Salle, por Adilson Cristiano Habowski, bajo la guía de la profesora Dra. Elaine Conte, titulada Teoría crítica de la tecnología y la educación: desafíos contemporáneos. El estudio, con un enfoque hermenéutico, discute los desafíos de las tecnologías en educación con el propósito de sospechar la razón técnica, unidireccional, de las recetas tecnocráticas derivadas de una tradición utilitaria y programada de enseñar el mundo de los negocios, basada en la teoría crítica y la teoría crítica. Filosofía de la tecnología. La investigación busca reconocer el potencial de movilizar, reconstruir y cuestionar el lenguaje de la tecnología en la educación, que debido a su ubicuidad puede vincular desorientaciones, alienaciones e inexactitudes, así como generar relaciones políticas de resistencia frente a las injusticias sociales.

PALABRAS CLAVE: Tecnologías. Educación. Desafíos Instrumentalidad técnica.

\section{RESENHA DA DISSERTAÇÃO}

A dissertação de Mestrado defendida no Programa de Pós-Graduação em Educação da Universidade La Salle, de Adilson Cristiano Habowski, sob orientação da professora Dra. Elaine Conte, intitulada Teoria crítica da tecnologia e educação: desafios contemporâneos, discute os desafios contemporâneos das tecnologias na educação com o propósito de suspeitar do modelo lógico-racional, de receitas tecnocráticas oriundas de uma tradição utilitarista, unidirecional e programada do ensino empresarial, tendo por base a Teoria Crítica e a Filosofia da Tecnologia.

A partir da abordagem hermenêutica, as problemáticas da dissertação gira em torno de duas questões: Que alternativas contra-hegemônicas podemos lançar para ultrapassar os domínios técnicos de ensino e fomentar diálogos formativos com os conhecimentos tecnológicos, para (re)pensar o abismo que separa a razão operacional de um projeto crítico e reflexivo das tecnologias na educação? As tecnologias na educação seriam uma velha aspiração para resolver os complexos problemas socioeducacionais ou uma inspiração ao questionamento, desafios e tensões com a educação intercultural do mundo digital? Tem como objetivo geral compreender as abordagens vigentes das tecnologias na educação, considerando as resistências e inércias em relação às pesquisas e práticas de educar, explicitando as interferências e as contradições formativas das tecnologias no campo do pensar e agir educativo-comunicativo.

A pesquisa tem seu alicerce na abordagem hermenêutica reconstrutiva voltada para a compreensão dos textos e discursos (HABERMAS, 1987). A abordagem hermenêutica reconstrutivista considera o sujeito descentrado e justificado na relação com o outro e no agir comunicativo voltado ao consenso. Considera o mundo enquanto um processo de reflexão 


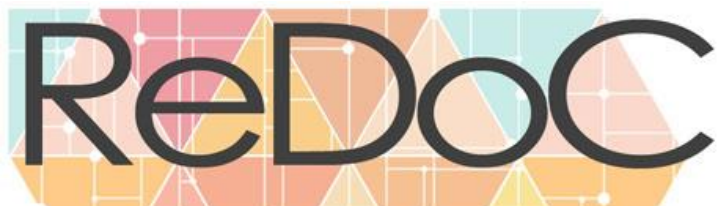

\section{Revista Docência e Cibercultura}

crítica e validação das abordagens. A pesquisa, pelo descentramento do sujeito, considera as forças sociais, econômicas e a evolução do cenário, e sua técnica não é fechada, formatada. Para Habermas (1987), a hermenêutica reconstrutiva designa o procedimento de resgate de elementos da tradição clássica e iluminista, agora apresentados na perspectiva intersubjetiva e dialógica da linguagem, democratizando e reconstruindo o que antes era proposto por uma razão monológica. Para Habermas (1987), entretanto, falta a dimensão da referência crítica das ideologias que pode atravessar os discursos situados no contexto histórico e necessitam da reflexão do intérprete sobre o aparato digital. Habermas (1987) afirma ainda que vivemos no paradigma moderno, cujo projeto de esclarecimento ficou inacabado, por isso, precisamos manter em aberto as diferentes perspectivas reconstrutivas do diálogo hermenêutico, enquanto observadores e participantes num fenômeno educativo e social que é atravessado, do princípio ao fim, pela questão do outro.

A proposta visa também despertar o intercâmbio de experiências para pensar a tecnologia como dimensão sociocultural e criativa da vida humana, para além dos condicionamentos e desvios operados por uma prática técnica dirigida por interesses do dinheiro e poder, da lógica programada do mercado. Por isso, a necessidade de reconstruir, a partir da abordagem hermenêutica, os potenciais colaborativos das diferentes interfaces com as tecnologias digitais na educação para prevenir práticas de exclusão, desumanização ou alienação tecnocientífica, que atinge a maioria dos percursos de formação.

A partir de abordagens evidenciadas e das mais recentes que estabelecem diálogos com a educação, surgiu a necessidade de aprofundar os entrelaçamentos pedagógicos com base nos Teóricos Críticos e na Filosofia da Tecnologia, identificando as dificuldades e possibilidades de problematização das tecnologias na educação, com vistas a elucidar as contradições formativas do como é desencadeado esse conhecimento tecnológico na leitura pedagógica, que, muitas vezes, robotiza as práticas sociais de educar.

Essa temática é de grande relevância, visto que as tecnologias são parte constituinte nos processos que modelam a existência humana, sendo pouco problematizadas em termos de análise filosófica e pedagógica no contexto capitalista em que vivemos. Tal iniciativa procura realizar um reagendamento da teoria crítica da tecnologia, tendo em vista os contextos sociais e educacionais, caracterizados pela presença das tecnologias digitais em todas as esferas da vida. Assim, apresentamos na próxima seção a caracterização do estudo, com os problemas de pesquisa, os objetivos (geral e específicos) e a abordagem metodológica.

A dissertação é organizada em cinco partes. Na primeira é apresentada a delimitação da pesquisa, a problemática e o percurso metodológico nos contextos investigados. Na segunda parte, discute-se teses de doutorado produzidas nos Programas de Pós-Graduação em Educação das universidades públicas do país, circunscritas à temática interações dialéticas com os conteúdos tecnológicos. Na sequência, abre-se os diálogos com os principais conceitos da Teoria Crítica, a atualidade nas interfaces educacionais tecnológicas, bem como sobre a 


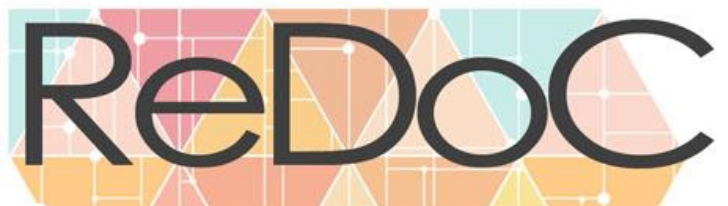

\section{Revista Docência e Cibercultura}

Filosofia da Tecnologia em Andrew Feenberg (1999; 2002) e a (auto)exploração social, relações de poder e traços totalitários no enxame digital, a partir de Byung-Chul Han (2018a; 2018b). Além disso, problematiza as tecnologias na educação, os desafios e enfrentamentos à tradição instrumental, reflexões sobre as experiências tecnológicas de distribuição de recursos nas escolas públicas, tecendo elos com as interpretações normalizadoras da inclusão digital. E, por fim, elenca-se os desafios na formação de professores para além do sentido técnicooperacional, para evitar retrocessos, seguido das considerações finais.

Portanto, trata-se de (re)pensar e questionar os limites das tecnologias na educação, trazendo as dimensões críticas e sociais ocultas no próprio conceito de tecnologia, como forma de provocação des-reificante dos processos de colonização cultural de ensino orquestrados pelo interesse técnico do mercado que leva à instrumentalização dos sujeitos, à violência contra si mesmo como realização, à exaustão do trabalho humano e pedagógico. O uso linear, técnico e acrítico das tecnologias pode representar a dependência e a insuficiência crítico-argumentativa, em função da mera informação descontextualizada, repercutindo em apropriações unívocas e destituídas de sentido porque, muitas vezes, surgem por decreto, subordinação ou modismo, não dialogando com as ações pedagógicas, que englobam a arte de compreender as tecnologias pela capacidade crítica. Para Selwyn (2017, p. 88), "as únicas perguntas que tendem a ser propostas seriamente à educação e tecnologia são aquelas relacionadas a o que funciona?... ou, mais frequentemente, o que poderia funcionar". Contudo, não se trata de resolver as questões de "efetividade ou melhor prática. Claramente, precisamos desafiar todas as hipóteses predominantes na área - mesmo que seja apenas para melhor nos informarmos sobre quais, exatamente, seriam os aspectos benéficos da tecnologia (e, consequentemente, quais não o seriam)". (SELWYN, 2017, p. 88).

Com base em Adorno e Horkheimer (1985), a dissertação aponta que a nossa sociedade atingiu grande desenvolvimento tecnológico, mas ao mesmo tempo, a humanização do sujeito tornou-se cada vez mais precária. $\mathrm{O}$ investimento em formação técnica é a deliberação oferecida para a escola brasileira, na tentativa de acompanhar as mudanças globais diante do surgimento das redes nos processos produtivos, para que os estudantes consigam fazer uso dos dispositivos eletrônicos para o mercado de trabalho, oferecendo respostas inadequadas para os problemas cotidianos e adaptando os processos em produtos, cujos potenciais das na educação não são alcançados. Há um descompasso entre a produção tecnológica e a formação pedagógica, que impõe em caixas de equipamentos soltos e de baixa qualidade a solução para os problemas enraizados historicamente na educação, quando sabemos que a maior batalha ao desenvolvimento educativo passa pela formação crítica de professores, pois nela se concebem utopias de linguagem.

Os desafios das tecnologias na práxis educativa vêm à cena como um saber social de interdependência, que ganha sentido na reconstrução comunicativa com o outro, no sentido de desenvolver uma relação humano-computador mais emancipadora e menos dependente da 


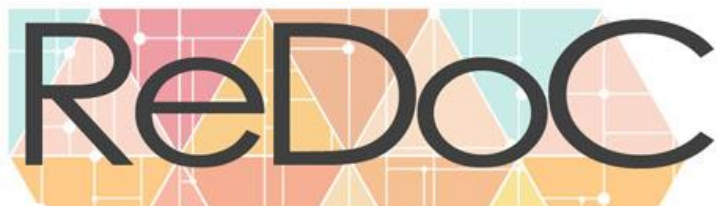

\section{Revista Docência e Cibercultura}

técnica. Colocar em questão as tecnologias na educação é algo complexo, pois implica transitar entre o inovador e o tradicional, de modo a articular a cultura digital ao engenho teórico e ao reconhecimento da prática pedagógica, reconstruindo uma relação com os processos vividos nos contextos escolares. O mundo contemporâneo está permeado por aparatos tecnológicos, que vêm à cena social como um saber, contendo diversas informações e possibilidades, que tanto provocam dependência técnica (fetiche, mercadoria, falsa liberdade, fantasias que ameaçam a história real) quanto a elaboração de novas questões, ideias, o entrecruzamento de fronteiras e curiosidades geradas em visões de mundo discordantes e não-lineares. A questão recai sobre o modo como utilizamos tais meios, uma vez que estes podem, ao mesmo tempo, nos trancafiar em um sistema alienante de práticas convencionais (seduzir pelo fetichismo aparente e a-histórico da vida alienada como a crença na terra plana), ou nos lançar em infinitos mundos de ações comunicativas com potencial reflexivo, contraditório, curioso, crítico, reconstrutivo e de emancipação coletiva (evolução social) (SANTAELLA, 2019; ADORNO, 1995).

A tecnologia, isoladamente, não é uma solução mágica para os problemas da educação, mas quando aliada à prática social e à interação humana pode contribuir para a (re)construção coletiva de aprendizagens. Os desafios da formação de professores são interdependentes das ações humanas e dos planejamentos das aulas com as tecnologias digitais no campo educacional. Os professores se vêm obrigados a repensar seus planejamentos educacionais em meio a tantas cobranças institucionalizadas e mudanças decorrentes dessa gestão compartilhada do conhecimento, que está vinculada aos interesses políticos, tecnológicos, econômicos e midiáticos. Isso tem reflexo direto na formação humana, já que todos somos afetados e precisamos participar de uma educação que não seja anacrônica, mas que nos humanize e não nos fragilize ainda mais. Os professores esquecem que os artefatos tecnológicos funcionam de fora para dentro, armazenam e processam informações, não conseguindo interpretar os conhecimentos em relação dialógica com os saberes e as formas de vida.

Considerada a importância de uma reflexão constante sobre os limites e possibilidades das tecnologias na cultura educacional, Habowski (2019) reafirma a necessidade de formação de professores para uma mudança de roteiro em relação ao sentido educativo das tecnologias, que ultrapasse o domínio da instrumentalização para que tenha alicerces na reflexão compartilhada, de abertura a (re)construção e ressignificação dos fazeres e saberes, viabilizando experiências capazes de transformações das relações sociotécnicas. Nesse sentido, as distintas práticas pedagógicas dos professores têm muito a colaborar com os processos de autorreflexão e descentramento comunicativo, que passa também por políticas de incentivo à formação de professores para desenvolver condições mínimas de um planejamento e de uma prática social de educar. Só assim é possível incluir as tecnologias digitais para além de um pacote imediatista, robotizado, descontextualizado das experiências na cultura escolar ou incompreendido. 
A rigor, não é possível negar a presença das tecnologias em nossas realidades educacionais, pois são parte constitutiva e dinâmica do processo de construção do conhecimento na contemporaneidade. E não há como negar que as tecnologias digitais possam ser integradas ao contexto educacional, para potencializar as práticas pedagógicas, no aprofundamento epistemológico, científico, técnico, metodológico e profissional, desde que passem pelo crivo da crítica e da possibilidade de reconstrução. (HABOWSKI; CONTE; TREVISAN, 2019). Estes precisam ser vistos como uma oportunidade de múltiplas aprendizagens coletivas, inseridos nos espaços de ensino e pesquisa para a discussão de temáticas relevantes para a construção e formação dos estudantes. Essa experiência de reaprender com o remanejo dos saberes, das culturas e das crenças, e com reagendamento das pesquisas com as tecnologias na educação implica fazermos parte do que é compreendido, afinal de contas, as conquistas tecnológicas dependem das esferas de interação humana e realização das ciências que é obra plástica e sutil da vida, e algo intrinsecamente pedagógico.

A dissertação é concluída afirmando que para ultrapassar a operacionalidade técnica e normativa inscrita e projetada na educação é necessário expandir os horizontes reflexivos com base no pensar (auto)crítico, buscando elucidar as contradições da aplicação do saber de interesse tecnológico, como forma de ressignificar as bases formativas em ações reconstrutivas, curiosas e apropriadas nas práticas pedagógicas. Para dar sentido às tecnologias na educação precisamos ressignificar os conhecimentos existentes, os enraizamentos históricos da arte de educar, que passa pela formação pedagógica e pelo empenho na problematização dos contextos, é preciso observar as interações humanas com essas novas tecnologias e provocar processos de reflexão-ação na cultura escolar.

\section{REFERÊNCIAS}

ADORNO, Theodor; HORKHEIMER, Max. A Dialética do Esclarecimento. Rio de Janeiro: Jorge Zahar, 1985.

ADORNO, Theodor W. Educação e Emancipação. Rio de Janeiro: Paz e Terra, 1995.

FEENBERG, Andrew. Questioning Technology. London and New York: Routledge, 1999.

FEENBERG, Andrew. Transforming Technology. New York: Oxford University Press, 2002.

HABERMAS, Jürgen. Dialética e Hermenêutica: para a crítica da hermenêutica de Gadamer. Trad. Álvaro L. M. Valls. Porto Alegre: L\&PM, 1987. 


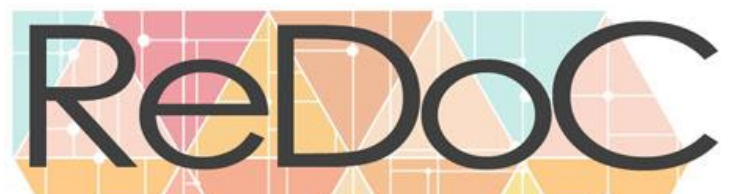

\section{Revista Docência e Cibercultura}

HABOWSKI, Adilson Cristiano. Teoria crítica da tecnologia e educação: desafios contemporâneos. 2019.153 f. Dissertação (Mestrado em Educação) - Universidade La Salle, Canoas, 2019. Disponível em:

<http://repositorio.unilasalle.edu.br/bitstream/11690/1249/1/achabowski.pdf> Acesso em: 9 jun. 2020.

HABOWSKI, Adilson Cristiano; CONTE, Elaine; TREVISAN, Amarildo Luiz. Por uma cultura reconstrutiva dos sentidos das tecnologias na educação. Educação \& Sociedade, Campinas, v. 40, n. 2, p. 1-18, 2019. DOI: 10.1590/es0101-73302019218349

HAN, Byung-Chul. No enxame: perspectivas do digital. Trad. Lucas Machado. Petrópolis, RJ: Vozes, 2018a.

HAN, Byung-Chul. Psicopolítica: o neoliberalismo e as novas técnicas de poder. Belo Horizonte: Editora Âyinê, 2018b.

SANTAELLA, Lucia. A Pós-Verdade é verdadeira ou falsa? Barueri, SP: Estação das Letras e Cores, 2019.

SELWYN, Neil. Educação e Tecnologia: questões críticas. In: FERREIRA, Giselle Martins dos Santos; ROSADO, Luiz Alexandre da Silva; CARVALHO, Jaciara de Sá (Org).

Educação e Tecnologia: abordagens críticas. ROSADO; Carvalho. Rio de Janeiro: SESES, 2017, p. 85-103.

Este é um artigo de acesso aberto distribuído sob os termos da Licença Creative Commons Atribuição Não Comercial-Compartilha Igual (CC BY-NC- 4.0), que permite uso, distribuição e reprodução para fins não comerciais, com a citação dos autores e da fonte original e sob a mesma licença. 